\title{
Introduction to the Special Issue ICTs and Society - A New Transdiscipline? What Kind of Academic Field Do We Need to Meet the Challenges of the Information Age?
}

\author{
Joseph E. Brenner* \& Celina Raffl** \\ * joe.brenner@bluewin.ch, International Center for Transdisciplinary Research, Paris, France \\ ${ }^{* *}$ celina.raffl@gmail.com, Public Policy at the Central European University (CEU), Budapest Hungary
}

Information and Communication Technologies (ICTs) have changed our lives significantly over the last few decades, and they will continue to do so. ICTs influence the way we live, work, and organize. These changes we are facing as societies (and as individuals) bear positive and negative side effects that concern academia as well, since science and research serve a function in and for society. What kind of academic field do we need to meet these challenges of the information age?

Many different research approaches have emerged over the last decades that aim at explaining, shaping, and forecasting social change related to an increasing penetration, miniaturization, and convergence of ICTs.

tripleC suggests the designation of this research area as ICTs-and-Society to indicate its broad perspective. The term ICTs itself is broad enough to capture Internet, Web, Web 2.0, Social Media, Social Networks, new mobile technologies, ambient technologies, etc. Society too, can refer to society at large, or to certain aspects, of society, such as economy, ecology, politics, culture, etc., and includes both individuals and organizations. The fact that "ICTs-and-Society" involves the disciplines of information and computer science, economics, sociology and political science, psychology and philosophy, etc., and additionally transcends the academic boundaries and at least affects, if not integrates, stakeholders from politics, economy, organizations, and individuals, suggests that ICTs-and-Society is a transdisciplinary field of research par excellence.

\section{The Current Disciplinary Context}

There is a major problem besetting all philosophical, metaphysical and epistemological thought about science, mind, morality and society. Competitive pressures for recognition and employment have always been a part of intellectual enterprise, and the geometric growth in the volume of information available via publications and conferences has obviously led to fragmentation and specialization of disciplines. A form of Darwinian selection operates to insure the 'survival' of favored species, that is, groups of researchers that have built strong structures capable of attracting support from the society at large.

Today's 'culture medium' is extraordinarily rich, and many areas of cognition, such as personal identity, for example, are receiving the directed attention they deserve. Ethical issues are addressed within the domain of information theory, as in the Luciano Floridi's Information Ethics (e.g. 2010; 2011), and most of the social science disciplines pay attention to environmental issues. Such interdisciplinary aspects are also recognized as essential for bringing new perspectives to specific problems requiring creative solutions, in domains that both do and do not directly involve the new Information and Communication Technologies (ICTs) of concern to this Journal except as tools for research.

It is not surprising, under these circumstances, that few people have the time or resources to focus on a broad evolutionary view of the academic disciplines and the society in which they are embedded. Any thoughts along these lines do not go beyond vague intuitions, as a basis for their serious consideration if such exists, is not widely known or discussed. The strong 'in groups' tend 
to resist, as distractions, new ideas or overall broad approaches that might require if not revision of the basic tenets of their theories, consideration of the validity of alternate approaches. Given the vast amount of non-science and non-sense that also circulates freely as consequence of the information tools now available, their resistance can be justified in terms of survival. Simplistic theories composed of dichotomous elements tend to be logically and mathematically tractable, offering literally and figuratively a path of least resistance to further publication.

On the other hand, it may well be true that without broad perspectives that enable people to have some distance from their disciplinary work, it may lose much of its critical as well as social value. The question then becomes how to encourage the development of such perspectives and find ways of distinguishing them, without marginalization, from the mass of prestigious journals, books and meetings that attract the majority of effort.

\section{Transdisciplinarity}

The concept of what has come to be called transdisciplinarity has been variously defined. Several definitions of transdisciplinarity exist, notably the one of Gibbons, and Nowotny and her colleagues at the University of Zurich (Gibbons \& Nowotny, 2002). This is a pragmatic view centered on approaches to solving concrete problems. Transdisciplinarity, in the more universal definition of Basarab Nicolescu (i.e. 2002; 2008) concerns that which is at the same time between, across and beyond all disciplines, the things they have in common. Its objective is the comprehension of the current world, of which one of the imperative necessities is a unity of knowledge. It is a theory that places the human being at the center of its preoccupations, and this view has greater generality and is the one more suitable to discussing issues in education, ethics and other aspects of social theory.

To ask the question "ICTs and Society: A New Transdiscipline?" implies logically that there are existing transdisciplines and that there may be other new ones. The term transdiscipline is itself a neologism, but it has been adopted in a number of areas, either simply as a discipline which serves other disciplines as a tool, while also having an autonomous status as a discipline in its own right, or a coherent set of research topics shared by distinct academic disciplines.

The subject of the Special Issue is not what transdisciplinarity and transdisciplines are per se, but the perhaps unavoidable conclusion, even from this study, is that the concepts are fated to remain vague and the terms polysemic. In our view, transdisciplinarity should not be seen as yet another discipline but as an aid to legitimizing and insuring a minimum scientific rigor in creative new approaches to on-going issues, here, as they relate to the emerging Information Society being (cf. the article by De Paoli et al. in this special issue) "Trustworthy".

As perhaps the broadest structure dealing with transdisciplinarity, grouping the sources cited and many others, we note on-line "The Academy of Transdisciplinary Learning \& Advanced Studies (ATLAS)", http://theatlas.org. Without the indicated concept of Nicolescu, however, it would be difficult to distinguish the ATLAS definition of a transdisciplinary approach from an interdisciplinary one.

\section{Information and Communication Technologies}

The term Information and Communication Technologies (ICTs) covers, in and of itself, an extremely broad range of knowledge, skills and disciplines. That these technologies have a large and rapidly expanding role in society, that merits analysis from both a theoretical and practical standpoint, is self-evident. Many authors have recognized the way in which the ICTs are changing social relationships and interactions, both positively and negatively, from the points of view of philosophy, information and computer science, psychology and sociology, to mention only a few of the disciplines concerned, as indicated in the Call for Papers.

The Editors of this Special Issue of tripleC, however, have asked themselves whether there is and/or should be a global perspective from which to evaluate the impact of the ICTs, due to the 
apparently unavoidable fragmentation and specialization of the classical disciplines which has accompanied technological development.

Some initial answers to this question will be found in the following articles. We consider them still partial, since the newness of the concept shows little consensus in either the methodology or the content of the transdiscipline that "ICTs and Society" can be considered to be. This result is not necessarily a negative one. As noted above, the last thing that is needed today is yet another carefully delineated discipline or field of study adding yet another to the multitude already existing. The following brief comments will indicate the scope of this problem, as background to a critical reading of the articles themselves.

Hofkirchner, in his contributions to an earlier issue of tripleC (2010), has proposed a taxonomy of theories about the relation between ICTs and society, and other articles deal with related concepts of convergence and conceptualization from a science and technologies studies (STS) standpoint. The current Volume can be seen as a further elaboration of the earlier transdisciplinary conception of Hofkirchner and his colleagues (2007) of the requirements for a theory of the ICTs and society.

The "logic of transdisciplinarity" (Brenner, 2008) in the Paris school acceptation of transdisciplinarity (Nicolescu, 2002), further supports the proposal that the techno-social field of study of ICTs and Society is a transdiscipline or transdisciplinary, as it also is directed, ultimately, toward a unity of knowledge. In our view, integration into the study of the concept of transdisciplinarity in these senses is necessary to raise the debate about the Information Society beyond the limits imposed by naïve pragmatism and conservative (not to say neo-liberal) ideologies toward a compassionate science.

The field or topic of transdisciplinarity, in our point of view, includes another philosophical or meta-philosophical dimension which is by no means, however, to be considered as irrelevant to the practical goals of this Journal, namely Cognition-Communication-Cooperation for a Global Sustainable Information Society. Criticisms of simplistic approaches are necessary, but they do not completely answer the question of why they are made and whether they will continue to be made. Another way of stating the problem is a need for the concomitant perspectives of sociology and evolutionary psychology, without becoming lost in a welter of disciplinary detail. Perhaps the 'disciplinary' term that would be most appropriate to our conception of transdisciplinarity is that it is a 'metaethical' approach, in which the moral consequences of the evolving ICTs are maintained in the foreground of the analysis.

In one definition of transdisciplinarity (Raffl, 2009): Transdisciplinarity is fostered as a new mode in research, allowing diverse groups of stakeholders, like politicians, practitioners or entrepreneurs to participate in research and development. Such an approach bears the risk, however, of not only being research with stakeholders, but for them and thus creating results in favor of the industry. It is the broader transdisciplinary approach, in the view of the Editors, which is illustrated in different ways in the Articles in this Special Issue. We may then say, logically, "ICTs and Society" is a transdiscipline, the academic field to meet the challenges of the information society, without falling into circularity.

\section{Comments on Specific Articles in this Volume}

In this Special Issue the concepts of both transdisciplinarity and transdiscipline have received a very varied treatment, which in a sense is entirely appropriate. The relation between ICTs-andSociety is viewed realistically, in both its positive and less positive aspects. As also seen in the contribution by DePaoli in this issue, transdisciplinarity rather than interdisciplinarity, in which separation between disciplines is largely maintained, should be the preferred paradigm for future research.

The selected, and in this special issue collected, contributions are in line with this understanding of transdisciplinarity. Transdiscplinarity is something distinct from interdisciplinarity in two respects: first, as regards the scientific status, i.e. not just a "combination of existing disciplines - in the case of "ICT and society" a mere combination of technology and social science -, but a transgression of the traditional borders of the participating disciplines and thereby a transformation of the disciplines 
into something new which has its own identity" (Hofkirchner et al., 2007, p.7) and second, regarding the societal function of science, transdisciplinarity does not adhere to the "long held assumption of science being in an ivory tower, but implies a transgression from the scientists to the stakeholders affected by the results of research and a transformation into a new science that is human-centred, democratic, participatory" (Hofkirchner et al., 2007, p.12).

The first four articles by Moore, Alonso et al., Bennett \& Sterling, and Fuster Morell focus on the role of universities and research institutes that conduct research in ICTs-and-Society.

Gale Moore argues for an Institutional Innovation that is required in order to support transdisciplinary research efforts within universities. Such an innovation, however, is challenging one, since transdisciplinarity "disrupts the traditional academy". Questions discussed in the contribution include as to whether transdisciplinarity can be accomplished within universities, in particular considering traditional institutional boundaries? What are the challenges, both structural and intellectual of doing transdisciplinary research in the university, and how can transdisciplinarity be accomplished in this context?

Luiza Alonso, Jean Sallantin, Edilson Ferneda, and Dominique Luzeaux discuss which tools are used to create and disseminate knowledge among scientists and stakeholders. The authors present a structural framework exemplified on "Scientific Knowledge Management Anchored on Socioenviromenmental Systems". The objective of the the structural framework is to provide a theoretical foundation with computational efficiency to multi-, inter-, and transdisciplinary scientific work. The reflection shows the different contexts that act on it: "its operational technique, its political significance, and its epistemological limits".

In their contribution "Computer Science is not enough" John K. Bennett and S. Revi Sterling criticize prevailing approaches in ICTs for Development (ICTD) research by questioning whether we are we doing ICT for Development, or ICT and Development? They argue that current approaches still emphasize on the later, i.e. a perpetuation of a model, where technological knowledge is used in development interventions. Therefore, most projects fail because of "a lack of breadth in project design and implementation, and in the training of project implementers". ICT for Development, in contrary, is about creating technologies "that have the potential to catalyze social change, and mapping human needs to technologies that directly respond to specific development problems". An overview of research institutes that provide education in ICTD is attached.

Mayo Fuster Morell's article focuses on methods on methodologies for transdisciplinary ICTsand-Society studies. She illustrates this issue with focusing on ICTs in and for social movement research. First, she reviews the main methodological trends and methods related to ICTs adopted in social movement research by discussing different types of relationships between research goals and ICTs, second emerging methodological approaches and methods using ICTs applied in social movement studies are assessed. In the following sections advantages and challenges of ICTs in research are critically evaluated. The paper concludes with suggesting that "ICT research should be approached with the search for an equilibrium between prudence and experimentation".

The last two contribution in this issue is more focussed on important concepts of the information society, i.e. citizenship and participation (Svensson) and trust for the future internet (DePaoli et al.).

Citizenship is according to Jakob Svensson ideally approached from a transdisciplinary view point. Citizenship is often discussed with "normative macro-perspectives of the good society [...] often departing from micro-empirical studies of how society and political participation are changing". Citizenship is also connected to ICTs since they gained importance for communicating in connected communities and became meaning to individuals as well as society. Society and technology mutually reinforce each other. Svensson's article contributes to the theoretical discussion of citizenship for better understandings and analyses of political participation in networked and individualized societies. The paper concludes with a proposal of how to categorize online participation and citizenship(s) in ICT societies.

Stefano De Paoli, G.R. Gangadharan, Aphra Kerr, Vincenzo d'Andrea discuss the importance of a transdisciplinary approach to achieve trust for the 'Future of the Internet' from a more practical 
than theoretical viewpoint. The "Future of the Internet does not just involve technological problems but has implications for the economy, society and governance". Trust needs to be understood as the outcome of the design rather than its precondition and this Trust as Result cannot achieved just by integrating different disciplines, but rather with a "movement that transcends disciplinary boundaries." To reach this goals it is important to reject a separation between a technical and a social object and to rely on concepts that transcend common assumed separations.

In summary, this special issue of tripleC comprises high quality research papers demonstrating the broad range of issues, challenges, and perspectives related to the question if ICTs-and-Society research is a new transdiscipline. The research field itself is still in an early stage; however, the scientific community is growing, platforms and networks dealing with this topic are emerging and journals are established.

This tripleC special issue is one attempt to give scholars in the field of ICTs-and-Society research the opportunity to reflect on the status quo and to envision the future of ICTs-and-Society research. It offers innovative analysis that promotes and provokes further debate about ICTs-andSociety as a subject of study.

\title{
References
}

Brenner, J. E. (2008). The logic of transdisciplinarity. In B. Nicolescu (Ed.), Transdisciplinarity: Theory and practice (pp. 155163). Cresskill, NJ: Hampton Press.

Floridi, L. (2010). The Cambridge handbook of information and computer ethics. Cambridge, UK: Cambridge University Press.

Floridi, L. (2011). The philosophy of information. Oxford, UK: Oxford University Press.

Gibbons, M., \& Nowotny, H. (2002). The potential of transdisciplinarity. In J. Thompson Klein, W. Grossenbacher-Mansuy, R. Häberli, A. Bill, R. W. Scholz, \& M. Welti (Eds.), Transdisciplinarity: Joint problem solving among science, technology and society: An effective way for managing complexity (pp. 67-80). Basel: Birkhäuser Verlag.

Hofkirchner, W. (2010). A taxonomy of theories about ICTs and society. tripleC. Open Access Journal for a Global Sustainable Information Society, 8(2), 171-176.

Hofkirchner, W., Fuchs, C., Raffl, C., Schafranek, M., Sandoval, M., \& Bichler, R. M. (2007). ICTs and society: The Salzburg approach: Towards a theory for, about and by means of the information society. ICT\&S Center Research Paper Series. Number 3. Salzburg. Retrieved from http://icts.sbg.ac.at/media/pdf/pdf1490.pdf.

Nicolescu, B. (2002). Manifesto of transdisciplinarity. New York, NY: State University of New York Press.

Nicolescu, B. (Ed.). (2008). Transdisciplinarity: Theory and practice. Cresskill, NJ: Hampton Press.

Raffl, C. (2009). Meaningful to whom? Position paper for the workshop 'Towards criteria for sustainability and social meaningfulness in development'. tripleC. Open Access Journal for a Global Sustainable Information Society, 7(2), 425-428.

\begin{abstract}
About the Authors
Joseph E. Brenner

was born in Paris in 1934. After primary and secondary education in New York, he received B.A. and M.S. degrees from the University of Chicago. In 1958, he earned a Ph.D. in Organic Chemistry from the University of Wisconsin. His career was in the chemical industry (Du Pont de Nemours International) in R.\&D. and corporate development. In 1998, he began collaboration with the International Center for Transdisciplinary Research (CIRET) in Paris. His focus has been to make the logical system of the Franco-Romanian thinker Stéphane Lupasco (Bucharest, 1900 - Paris, 1988) accessible to English-language readers. Dr. Brenner is a member of the American Association for the Advancement of Science; the New York Academy of Sciences; and the Swiss Society for Logic and the Philosophy of Science. He recently joined the Editorial Board of tripleC.
\end{abstract}

\section{Celina Raffl}

Since September of 2011 Celina Raffl is a probationary PhD student at the Doctoral School in Public Policy at the Central European University (CEU). Prior to that she was a lecturer at the Eötvös Loránd University in Budapest for one year and held a scholarship from the Austrian Agency for International Mobility and Cooperation in Education, Science and Research. From 2004 until 2010 Celina was a research fellow at the ICT\&S Center at the University of Salzburg, Austria. [www.celina.uti.at] 